\title{
AOR
}

Selected Papers of \#AolR2021:

The 22nd Annual Conference of the Association of Internet Researchers Virtual Event / 13-16 Oct 2021

\section{'IT'S 1776, BABY!': BROADCASTING REVOLUTIONARY PERFORMANCE DURING THE U.S. CAPITOL RIOTS}

James N. Gilmore, Ph.D.

Clemson University

Madeline Hamer

Clemson University

Valerie Erazo

Clemson University

Patrick Hayes

Clemson University

\section{Introduction}

This paper focuses on the mediation of the January 6, 2021 breach of the U.S. Capitol by supporters of then-President Donald Trump in an effort to overturn the certification of Joseph Biden's electoral victory. We analyzed videos participants recorded and shared through seven different platforms: the social networking sites Facebook, Twitter, and Parler; the live-streaming sites DLive, Twitch, and Periscope; and the messaging application Snapchat. In examining this range of platforms and applications, we argue not just for the importance of attending to the documentation of violent protests, but to also account for the broad spectrum of possibilities at play across the ecology of digital video-sharing platforms in building digitally networked publics (Tufekci 2017) on the far right.

\section{Research questions}

RQ1: How did participants in the U.S. Capitol Riot use different online platforms to broadcast video content of this event?

RQ2: In what ways did participants in the U.S. Capitol Riot draw on imagery and language of revolution in the video content shared on online platforms?

\section{Method}

Suggested Citation (APA): Gilmore, J.N., Hamer, M., Erazo, V., and Hayes, P. (2021, October).'It's 1776, baby!': Broadcasting revolutionary performance during the U.S. Capitol Riots. Paper presented at AolR 2021: The 22nd Annual Conference of the Association of Internet Researchers. Virtual Event: AolR. Retrieved from http://spir.aoir.org. 
We accessed footage from the Capitol Riot through a public file sharing archive on the service MEGA. The contents of this folder were crowdsourced through data hoarders coordinating through the r/DataHoarder subreddit on the message board site Reddit. The MEGA folder did not provide identifying metadata for any videos we examined; the sample was anonymous. We selected seven platforms for analysis. Three of themDLive, Twitch, and Periscope-are primarily for live-streaming over a length of time. They allow users to stream continuous, real-time long-form videos up to several hours in length. We viewed live-stream footage from five DLive users totaling over six hours, three Periscope streams totaling over three hours, and three Twitch streams totaling over four hours. Three other platforms-Facebook, Twitter, and Parler-are more traditional social networking sites that utilize the relationships between users in various networks engaging with one another. We viewed fifty-eight videos shared through Facebook, fifty videos from Twitter, and thirty videos from Parler. Our seventh platform was Snapchat, a messaging application focusing on supposedly ephemeral transmission of still images and videos of up to ten seconds in length that are programmed to 'disappear' from public view after twenty-four hours. We viewed thirtyone Snapchat Stories.

We approached videos qualitatively and with an interpretivist position, using visual analysis to map both form (what is the camera doing, and how is the videographer using the technology to record the Riot) and content (what is represented in the frame itself). We interpret meaning based on visual evidence and we assume intent: Participants in the Capitol Riot had to make decisions to take out their phones or mobile cameras, to open different applications, to engage the streaming functions of their devices, and to click the necessary buttons to share and broadcast these videos. This is a choreography between human participant, media device, and platform infrastructure. The decision to, for instance, turn one's camera so that it faces the videographer (the "selfie" mode) is a meaningful decision about how a participant positions their face and body into the documentation of the event.

\section{Findings}

We identified six aesthetic themes-three for form and three for content. For form, we note the use of camera pans (moving back and forth from a relatively still position) to capture crowd size and activity outside the Capitol, selfies (using the front-facing camera on smartphones) to place the videographer in the frame and position their body as important to the documentation, and tracking (moving the camera through space) to mimic the style of embedded journalists. For content, we identified costume, which includes both attire like the red "Make America Great Again" caps many Trump supporters wear as well as an array of flags meant to illustrate loyalty to Trump and to cast this as a political revolution; speech, which includes anything from crowd cheers of phrases like "Fight for Trump" to individuals screaming "traitors" towards Capitol police officers; and songs, which include so-called "hype videos" produced and distributed mostly through Parler in the twenty-four period leading up to the Capitol Riot as well as spontaneous singing of the national anthem and Christian hymns during the course of the Riot. 
The participants in the Capitol Riot drew on a variety of symbols meant to coordinate anti-government revolution through their positioning of Trump as superior to the existing U.S. government (which is labeled as "traitors" in some speech), their invocation of multiple nationalist symbols emerging from prior historical moments of revolution, and connections to domains like religion and sport through hymns and hype videos. These symbols are mediated through formal choices like pans and selfies to emphasize relationships to the crowd and broadcast these symbols back to digital platforms. They indicate an aesthetics of dissent (Neumayer and Rossi, 2018).

We call this a revolutionary aesthetic-a mode of sensuous perception meant to cultivate affective sympathies towards an insurrection against the United States and a delegitimization of the democratic process. The goal of this revolutionary aesthetic is not just a means of displaying one's political identity and solidarity within a community of far-right organizers (DeCook, 2018). The revolutionary aesthetic is an ongoing strategy of far-right political participation in digital public spheres based on forging articulations across understandings of U.S. history, religion, sport, and fandom more broadly. Technologies like front-facing cameras on mobile smartphones and Facebook Live platform features are part of how representations of violence against the state become performed and aestheticized.

\section{Relevance}

AolR 2021 is focused on the relationship between "independence" and the internet. The conference's intended site of Philadelphia was, of course, a crucial location in the U.S. Revolutionary War; many of the participants in the U.S. Capitol Riots explicitly invoked this War, with variations of the chant "1776" drawing connections between this insurrectionist attempt at interfering with election certification and the country's founding war against the British. Our research shows how "independence" works as a floating signifier that gets absorbed by far-right militias and other nationalist groups to build support for violent actions. It is indicative of the contextual forms of "chaos" Grossberg (2018) has attributed to Trump(ism). Our research shows how "independence" was rearticulated through the Stop the Steal movement as a means for challenging the legitimacy of the federal government, and how that can be traced through the revolutionary aesthetic.

\section{References}

DeCook JR (2018) Memes and symbolic violence: \#proudboys and the use of memes for propaganda and the construction of collective identity. Learning, media and technology 43(4): 485-504.

Grossberg L (2018). Under the cover of chaos: Trump and the battle for the American Right. London: Pluto Press.

Neumayer C and Rossi L (2018) Images of protest in social media: Struggle over visibility and visual narratives. New Media \& Society 20(11): 4298-4310. 
Tufekci Z (2017) Twitter and tear gas: The power and fragility of networked protest. New Haven: Yale University Press. 